\title{
Linear lupus erythematosus profundus
}

\author{
Esra Pancar Yüksel*a, Fatma Aydınª, Levent Yıldız ${ }^{\text {, }}$, Müge Güler Özdena, Nilgün Şentürkª, Tayyar Cantürka, Ahmet Yaşar \\ Turanlı ${ }^{\mathrm{a}}$
}

Departments of Dermatology ${ }^{a}$ and Pathology ${ }^{b}$, Medical Faculty, Ondokuz Mayis University, Samsun, Turkey

\begin{tabular}{ll}
\hline ARTICLE INFO & ABSTRACT \\
$\begin{array}{ll}\text { Article History } \\
\begin{array}{l}\text { Received } \\
\text { Accepted }\end{array} \quad 04 / 12 / 2011\end{array}$ & $\begin{array}{l}\text { Lupus erythematosus profundus is grouped within the chronic cutaneous lupus erythe- } \\
\text { matosus and linear form of it has been rarely reported. Lesions are described as subcu- } \\
\text { taneous nodules and plaques with a distinctive distribution. We report a 16 years old girl } \\
\text { with lupus erythematosus profundus in whom the lesions were at the upper extremity and } \\
\text { showed a linear configuration following the lines of Blaschko. We also review the previ- } \\
\text { ous reported 12 cases of linear lupus erythematosus profundus in the literature. Patients } \\
\text { * Correspondence to }\end{array}$ \\
$\begin{array}{l}\text { Esth linear lupus erythematosus profundus had different features of age, racial charac- } \\
\text { teristics and distribution of lesions when compared with lupus erythematosus profundus. } \\
\text { Ondokuz Mayis University } \\
\text { Medical Faculty, }\end{array}$ & $\begin{array}{l}\text { J. Exp. Clin. Med., 2012;29:64-67 } \\
\text { Departmel }\end{array}$
\end{tabular}

Department of Dermatology

Kurupelit, Samsun, Turkey

e-mail: esrapancar@yahoo.com

\section{Keywords:}

Cutaneous lupus erythematosus

Linear distribution

Lines of Blaschko

Lupus erythematosus profundus

Hydroxychloroquine

Panniculitis

(C) 2012 OMU All rights reserved

\section{Introduction}

Lupus erythematosus profundus (LEP) is an unusual form of chronic cutaneous lupus erythematosus. It was first described by Kaposi in 1883 (Kaposi, 1883). Later, this clinical entity was named by Irgang in 1940 and established as a specific subtype of LE by Arnold in 1956 (Patterson, 2008). LEP presents with subcutaneous nodules and plaques mainly on the face, upper arms, hips and trunk. Light pink to red coloured lesions could show changes such as dyspigmentation, atrophy, scarring. Linear arrangement of the lesions in subtypes of cutaneous LE has been reported infrequently and among LEP patients, linear configuration has been described rarely. In this report we describe linear LEP (LLEP) in a young female and review the previous reported cases of LLEP in the literature (Tada et al.,1991; Innocenzi et al., 1997; Tamada et al., 1999; Nagai et al., 2003; Marzano et al., 2005; Choi et al., 2006; Shin et al., 2007; Rhee et al., 2009; Tamiya et al., 2010; Lee et al., 2011).

\section{Case}

Sixteen years old female patient admitted to dermatology clinic with the complaint of skin lesions on her upper extremity that gradually increased in number during the last six months.

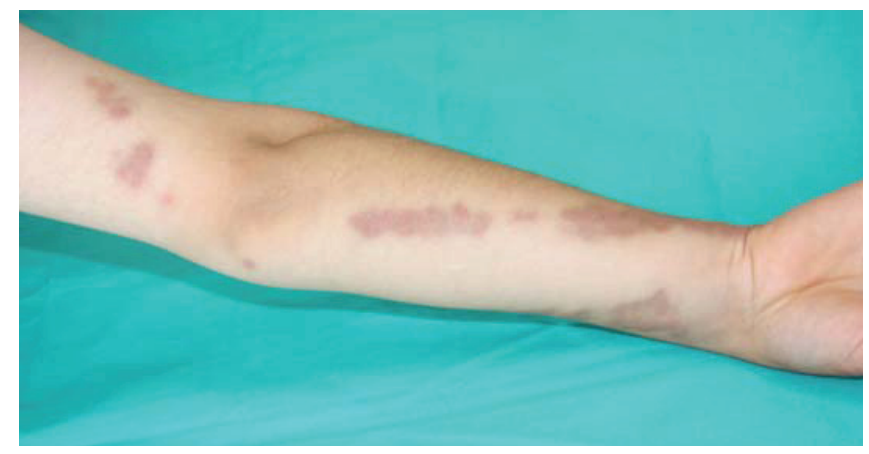

Fig. 1. Indurated plaques extending from the lower part of her right forearm to her right arm in a linear distribution. 
She was in good health without complaints of arthralgia and fever. Family history of any autoimmune disease was not present. No history of any trauma and infection was stated. Physical examination revealed indurated plaques extending from the lower part of her right forearm to her right arm in a linear distribution.

The lesions were consistent with the Blaschko lines (Fig. 1). The new lesions were red in colour. Hyperpigmentation was noticed in the older ones. No any other cutaneous changes such as atrophy and depression were recognized. Normal complete blood cell counts, liver and renal function tests, urine analysis, erythrocyte sedimentation rate were detected at laboratory investigations. Antinuclear antibody (ANA), anti-dsDNA antibody tests were negative. Two biopsies were taken; one from forearm, the other one was from arm. Histopathologic examinations of them showed similar features and reported as perivascular and periappendageal infiltrate of lymphocytic cells, vacuolar degeneration at the basement membrane zone, focal mucin deposition in the dermis and lymphocytic infiltration characterized as lobular panniculitis in subcutaneous tissue (Figs. 2, 3).

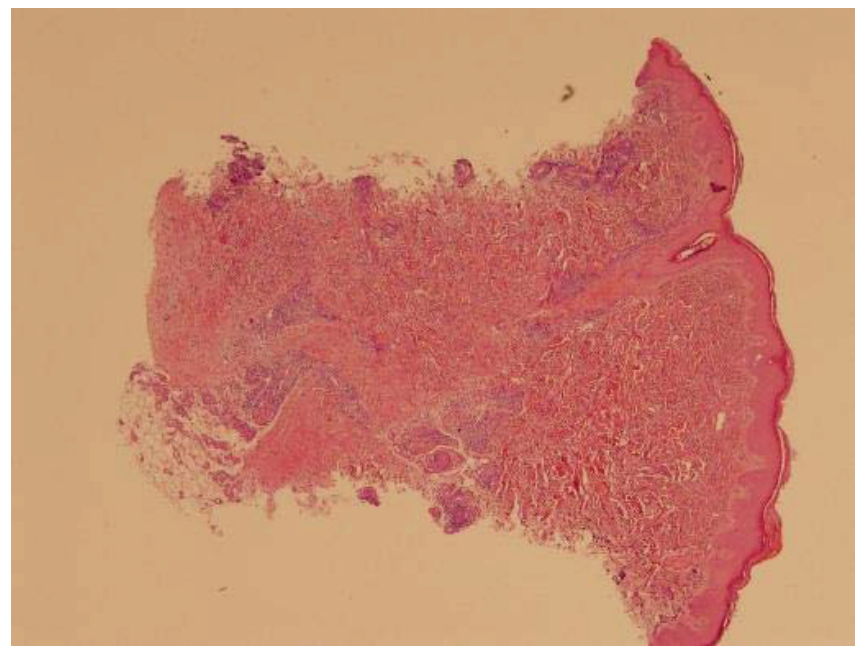

Fig. 2. Lymphocytic infiltration present in perivascular area of dermis and in subcutaneous tissue (H\&E, $\mathrm{x} 40)$.

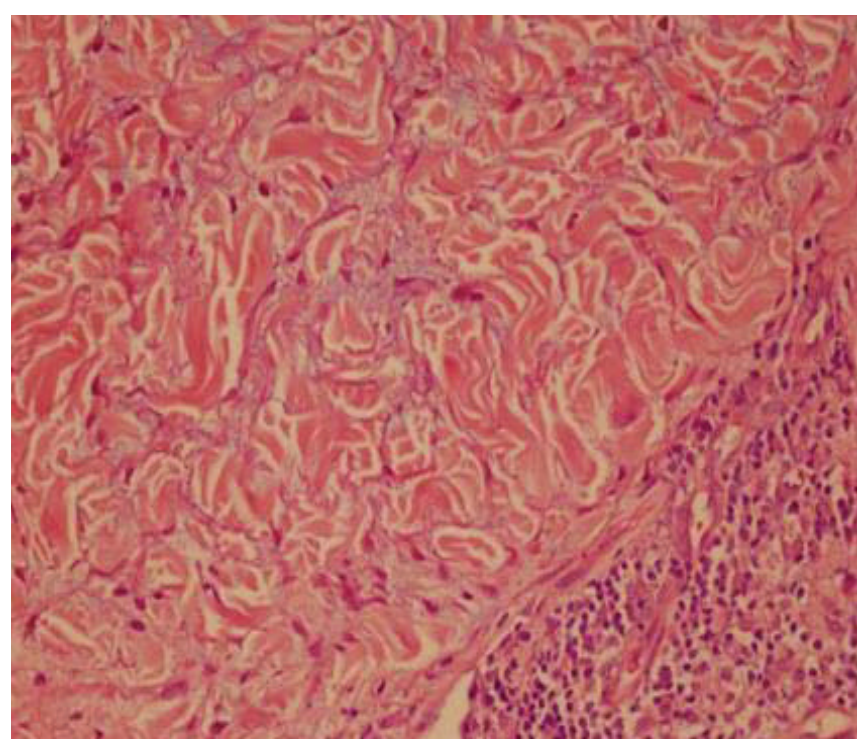

Fig. 3. Focal mucin deposition in the dermis and perivascular infiltrate of lymphocytic cells (H\&E, x 400).
Direct immunofluorescence microscopy was negative for IgA, IgM, and IgG. With these clinical and pathological findings, she was diagnosed as linear lupus erythematosus profundus (LLEP). A combination treatment of oral methylprednisolone $32 \mathrm{mg}$ /day and hydroxychloroquine $400 \mathrm{mg}$ / day was started. Concomitantly intralesional injection of triamcinolone acetonide $(5 \mathrm{mg} / \mathrm{ml})$ was also applied.

\section{Discussion}

Chronic cutaneous lupus erythematosus has different clinical variants and these were histologically defined according to the location and depth of the inflammatory infiltrate. Round or oval erythematous plaques with scales and sometimes with atrophy are the most common lesions clinically and linear configuration of these lesions has been reported rarely. LEP is a subset of chronic cutaneous lupus erythematosus in which the primary location of the infiltrates is subcutaneous fat. Skin lesions of LEP are characterized by subcutaneous nodules or indurated erythematous plaques. In the literature; linear form of LEP has been reported as a very rare entity. First case of LLEP was reported in 1991 by Tada et al. (1991), to our knowledge after those only 12 cases have been reported including our case (Innocenzi et al., 1997; Tamada et al., 1999; Nagai et al., 2003; Marzano et al., 2005; Choi et al., 2006; Shin, 2007; Rhee et al., 2009; Lee et al., 2011). Although Tamiya et al. (2010) reported this number as seven, they didn't reference the four Korean patients and one more case was reported after their report (Choi et al., 2006; Shin, et al., 2007; Rhee et al., 2009; Lee et al., 2011). We analyzed all reported LLEP cases up to now and noticed some distinct features of these patients according to nationality, age and association with Blaschko's lines (Table 1).

Linear LEP patients were young people. At the time of onset of the disease most of the reported cases were under 20 years of age, furthermore six of them were equal or under 15 years of age. This young population was noteworthy since LEP is very rare in children (Tada et al., 1991). LEP is usually seen in adults and median age of onset is 30-40 years-old (Martens et al., 1999). So it can be said that the age of patients with LEP and LLEP was quite different. Although LEP is predominant in females (Peters and Su, 1991; Martens et al., 1999) no obvious disproportion was recognized between genders among LLEP patients.

Patients with LLEP were reported mostly from Japanese or Korean population (Tada et al.,1991; Tamada et al., 1999; Nagai et al., 2003; Choi et al., 2006; Shin et al., 2007; Rhee et al., 2009; Tamiya et al., 2010; Lee et al., 2011). Four Japanese and five Korean patients were described among 13 patients (Tada et al.,1991; Tamada et al., 1999; Nagai et al., 2003; Choi et al., 2006; Shin et al., 2007; Rhee et al., 2009; Tamiya et al., 2010; Lee et al., 2011). Since cases were reported independently, predominance of Far East population was not mentioned in these papers. Lesions were localized particularly to the upper part of the body and especially to the head. Only two of them were located at the lower extremity. Distribution of the lesions was also a remarkable point. All 13 cases including ours were reported as a linear pattern (Tada et al., 1991; Innocenzi et al., 1997; Tamada et al., 1999; Nagai et al., 2003; Marzano et al., 2005; Choi et al., 2006; Shin, 2007; Rhee et al., 2009; Tamiya et al., 2010; Lee et al., 2011). 
Table 1. Linear lupus erythematosus profundus in the literature

\begin{tabular}{|c|c|c|c|c|c|c|c|c|}
\hline References & $\begin{array}{l}\text { Sex/ age } \\
\text { (year) }\end{array}$ & $\begin{array}{c}\text { Age of } \\
\text { onset }\end{array}$ & Country & Location & $\begin{array}{l}\text { Association of } \\
\text { blascho lines }\end{array}$ & ANA & DIF positivity & Treatment \\
\hline Tada et al. (1991) & $\mathrm{M} / 9$ & 3 & Japan & Left leg & - & - & - & Topical steroid \\
\hline $\begin{array}{l}\text { Innocenzi et al. } \\
\text { (1997) }\end{array}$ & $\mathrm{M} / 17$ & 14 & Italy & $\begin{array}{l}\text { Breast, right } \\
\text { arm }\end{array}$ & NK & + & IgM & NK \\
\hline $\begin{array}{l}\text { Tamada et al. } \\
\text { (1999) }\end{array}$ & $\mathrm{M} / 19$ & 18 & Japan & Arm & NK & - & IgM,C3 & IL steroid \\
\hline $\begin{array}{l}\text { Nagai et al. } \\
(2003)\end{array}$ & $\mathrm{F} / 10$ & 10 & Japan & Scalp & + & + & NS & Topical steroid \\
\hline $\begin{array}{l}\text { Marzano et al. } \\
(2005)\end{array}$ & $\mathrm{F} / 21$ & 21 & Italy & Scalp & NK & + & NK & IL steroid \\
\hline $\begin{array}{l}\text { Marzano et al. } \\
\text { (2005) }\end{array}$ & $\mathrm{F} / 32$ & 29 & Italy & Right arm & NK & + & IgM,C3 & $\begin{array}{c}\text { Metilprednisolone } 32 \mathrm{mg} / \mathrm{d} \\
\text { Hydroxychloroquine } 200 \mathrm{mg} / \mathrm{d}\end{array}$ \\
\hline $\begin{array}{l}\text { Choi et al. } \\
\text { (2006) }\end{array}$ & $\mathrm{F} / 8$ & NK & Korea & Face & + & - & + & $\begin{array}{l}\text { Metilprednisolone } 8 \mathrm{mg} / \mathrm{d} \\
\text { Topical steroid }\end{array}$ \\
\hline Shin et al. (2007) & $\mathrm{M} / 20$ & 15 & Korea & Scalp & - & + & $\operatorname{IgM}, \mathrm{A}, \mathrm{C} 3$ & $\begin{array}{l}\text { Prednisolone } 20 \mathrm{mg} / \mathrm{d} \\
\text { Cyclosporine } 200 \mathrm{mg}\end{array}$ \\
\hline Rhee et al. (2009) & $\mathrm{M} / 14$ & 14 & Korea & Scalp & + & NK & - & $\begin{array}{c}\text { Hydroxychloroquine } 400 \mathrm{mg} / \mathrm{d} \\
\text { Prednisolone } 20 \mathrm{mg} / \mathrm{d} \\
\text { IL steroid }\end{array}$ \\
\hline $\begin{array}{l}\text { Rhee et al. } \\
\text { (2009) }\end{array}$ & $\mathrm{NK} / 32$ & 30 & Korea & Scalp & + & NK & - & Dapsone $50 \mathrm{mg} / \mathrm{d}$ \\
\hline $\begin{array}{l}\text { Tamiya et al. } \\
\text { (2010) }\end{array}$ & $\mathrm{F} / 6$ & 6 & Japan & Scalp & & NK & $\operatorname{IgM}$ & Prednisolone $15 \mathrm{mg} / \mathrm{d}$ \\
\hline $\begin{array}{l}\text { Lee et al. } \\
\text { (2011) }\end{array}$ & $\mathrm{F} / 28$ & 26 & Korea & $\begin{array}{l}\text { Flank, right } \\
\text { thigh }\end{array}$ & + & + & NK & Hydroxychloroquine $400 \mathrm{mg} / \mathrm{d}$ \\
\hline Present case & $\mathrm{F} / 16$ & 16 & Turkey & $\begin{array}{l}\text { Right arm, } \\
\text { forearm }\end{array}$ & + & - & - & $\begin{array}{l}\text { Hydroxychloroquine } 400 \mathrm{mg} / \mathrm{d} \\
\text { Metilprednisolone } 32 \mathrm{mg} / \mathrm{d} \\
\text { IL steroid }\end{array}$ \\
\hline
\end{tabular}

M; Male, F; Female, NK; Not known, IL; Intralesional, ANA; anti-nuclear

Trauma or Koebner phenomenon was accused for this pattern but history of any preceding trauma was not present in all reported cases including ours. By recognizing linearity, Nagai et al. (2003) reported the lesion of their patient was consistent with Blaschko's lines. They hypothesized that an anomaly of the epidermis or adnexia could be the possible cause of LEP due to the monoclonality of these lines. In the reports after that, Blaschko's lines were discussed and five of the reported cases were also found to be related with this pattern, but the mechanism of distribution couldn't be found (Marzano et al., 2005; Choi et al., 2006; Shin, 2007; Rhee et al., 2009; Tamiya et al., 2010; Lee et al., 2011).

Also we noted lesions of our case compatible with B1aschko's lines. Blaschko's lines are developed by migration of skin cells during embryogenesis and considered to be the expression of epidermal mosaicism. Therefore, mosaicism for a mutation might be the mechanism affecting the trace of the migration of embryonic cells. Susceptibility to a particular subtype of cutaneous LE can be determined by molecular basis. In our opinion, gene expression patterns could be the key point for defining the LLEP. Also with the knowledge of the predominance of Far East population, we want to draw attention to possibility of LLEP being a different entity seen in a group of people with special genetic codes.

Some of the patients were examined for anti-nuclear antibody and direct immunofluorescence microscopy and both positive and negative results were reported.

Treatment of LLEP was not different from the cutaneous lupus erythematosus. Mainly systemic, topical and intral- esional steroid and hydroxychloroquine was used. Rhee et al. (2009) used dapsone $50 \mathrm{mg}$ /day for 12 weeks and reported regrowth of the terminal hairs on the lesion. Marzano et al. (2005) applied intralesional steroid injection to one of their patient and followed up her for nine years. Although alopecia had remained unchanged, lesion had resolved with a deep depression. None of the other cases were followed up for long term. We also started oral methylprednisolone $32 \mathrm{mg} /$ day and hydroxychloroquine $400 \mathrm{mg}$ /day together and intralesional injection of triamcinolone acetonide $(5 \mathrm{mg} / \mathrm{ml})$ was also applied. She showed improvement in her cutaneous manifestations and no new lesion was detected after three months. But follow up of patients should be extended for evaluation of treatment success.

We also noticed that the priority of the authors was different while giving information about the cases. ANA, anti dsDNA, family history of autoimmune diseases and history of trauma were not stated in some of the reports. Association with Blaschko's lines is important and should be highlighted. Presentation of information completely will help to provide more accurate knowledge about this disease.

In conclusion, the cause of the linearity of LEP lesions has not been explained exactly yet. Distribution along the lines of Blaschko was mentioned, but the mechanism is still unknown. Alteration in genes might be the cause. Also, features of age, racial characteristics, and distribution of lesions are different in reported cases of LLEP when compared with LEP. So, detection and reporting of each new case are of great value in order to understand and explain LLEP better. 


\section{REFERENCES}

Choi, W.S., Kim, J.W., Park, H.S., Jang, S.J., Choi, J.C., 2006. A case of linear lupus panniculitis in child. Korean J. Dermatol. 44, $1367-1369$. Innocenzi, D., Pranteda, G., Giombini, S., Silipo, V., Bottoni, U., Calvieri, S., 1997. Linear lupus erythematosus profundus in an adolescent. Eur. J. Dermatol. 7, 445-447.

Kaposi, M., 1883. Pathologie und therapie der Hautkrankheiten. Urban \& Schwarzenberg, Vienna, pp. 642.

Lee, H.E., Ko, J.Y., Lee, C.W., 2011. A case of lupus erythematosus panniculitis presenting as combined linear and lipoatrophic skin lesions. Int. J. Dermatol. 50, 203-205.

Martens, P.B., Moder, K.G., Ahmed, I., 1999. Lupus panniculitis: clinical perspectives from a case series. J. Rheumatol. 26, 68-72.

Marzano, A.V., Tanzi, C., Caputo, R., Alessi, E., 2005. Sclerodermic linear lupus panniculitis: report of two cases. Dermatology. $210,329-332$.

Nagai, Y., Ishikawa, O., Hattori, T., Ogawa, T., 2003. Linear lupus erythematosus profundus on the scalp following the lines of Blaschko. Eur. J. Dermatol. 13, 294-296.

Patterson, W., 2008. Panniculitis. In Dermatology, Vol. 2, Bolognia, J.L., Jorizzo, J.L., Rapini, R.P., eds. Elsevier, Spain. $1526-1527$.

Peters, M.S., Su, W.P., 1991. Eosinophils in lupus panniculitis and morphea profunda. J. Cutan Pathol. 18, 189-192.

Rhee, C.H., Kim, S.M., Kim, M.H., Cinn, Y.W., Ihm, C.W., 2009. Two cases of linear alopecia on the occipital scalp. Ann. Dermatol. 21, 159163.

Shin, M.K., Cho, T.H., Lew, B.L., Sim, W.Y., 2007. A case of linear lupus erythematosus profundus on the scalp presenting as alopecia. Korean J. Dermatol. 45, 1280-1283.

Tada, J., Arata, J., Katayama, H., 1991. Linear Lupus erythematosus profundus in a child. J. Am. Acad. Dermatol. 24, 871-874.

Tamada, Y., Arisawa, S., Ikeya, T., Yokoi, T., Hara, K., Matsumoto, Y., 1999. Linear lupus erythematosus profundus in a young man. Br. J. Dermatol. 140, 177-178.

Tamiya, H., Sowa, J., Nakanishi, T., Adachi, M., Ishii, M., Kobayashi, H., 2010. Linear lupus erythematosus profundus on the face, following the lines of Blaschko. Int. J. Dermatol. 49, 1454-1465. 